\title{
Numerical Study on Particle-Gas Interaction Close to the Substrates in Thermal Spray Processes with High-Kinetic and Low-Pressure Conditions
}

\author{
Georg Mauer ${ }^{1}$ \\ Forschungszentrum Jülich, Institute of Energy and Climate Research: IEK-1 \\ Jülich, Germany
}

\section{Abstract}

In thermal spray processes, the interaction between the gas jet and the particulate feedstock can affect the coating build-up mechanisms considerably. Especially under high-kinetic and low-pressure conditions, small particles are subjected to rapid deflection and velocity changes close to the substrate. In this work, numerical studies were performed to investigate the interaction between gas and particles in the substrate boundary layers (BL). Typical conditions for suspension plasma spraying (SPS), plasma spray-physical vapor deposition (PS-PVD), and aerosol deposition (AD) were taken as a basis. Particular importance was attached to the consideration of rarefaction and compressibility effects on the drag force. Typical Stokes numbers for the different thermal spray processes were calculated and compared. Possible effects on the resulting coating build-up mechanisms and microstructure formation are discussed. The results show that just for larger particles in the SPS process the laminar flow attached to the particles begins to separate so that the drag coefficients have to be corrected. Furthermore, slip effects occur in all the investigated processes and must be considered. The comparison of calculated Stokes numbers with critical values show

\footnotetext{
${ }^{1}$ Corresponding author:

Forschungszentrum Jülich GmbH: IEK-1

52425 Jülich, Germany

g.mauer@fz-juelich.de
} 
that there is a disposition to form columnar microstructures or stacking effects depending on the particle size for PS-PVD and SPS, but not for AD.

\section{List of Symbols}

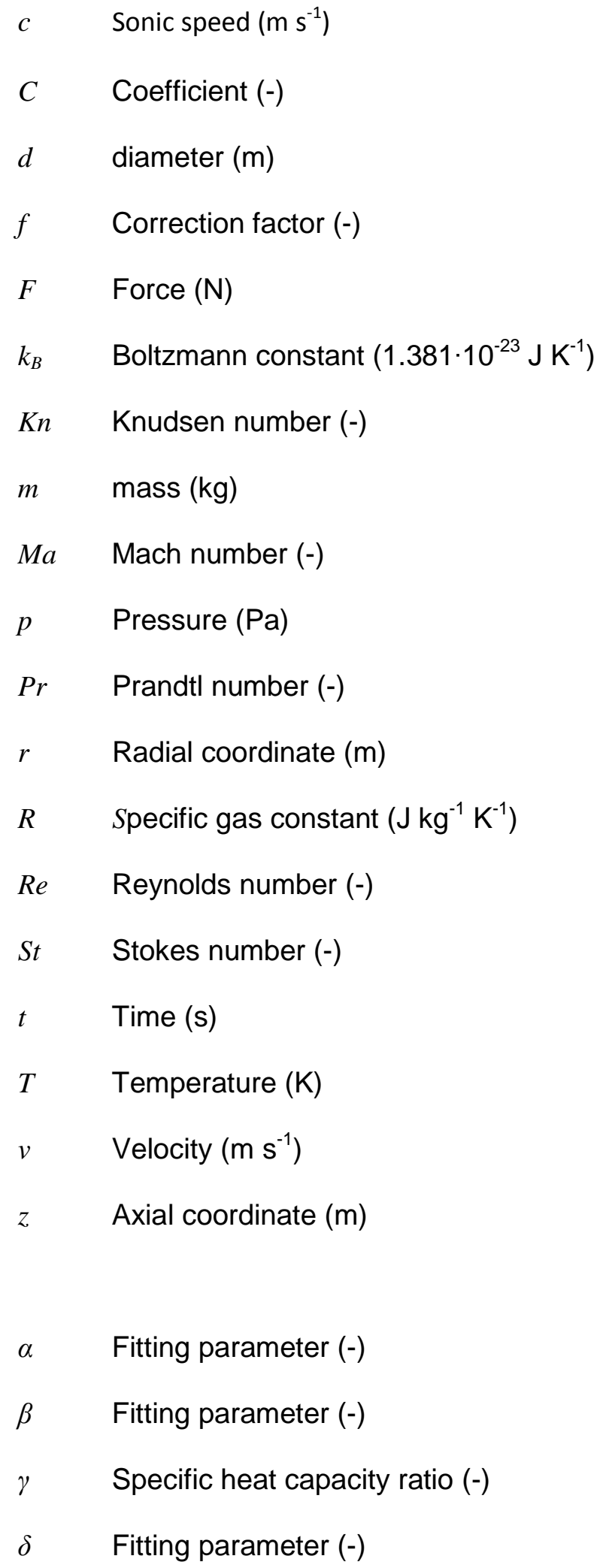


$\kappa \quad$ Curvature $\left(\mathrm{m}^{-1}\right)$

$\lambda \quad$ Mean free path length $(\mathrm{m})$

$\mu \quad$ Dynamic viscosity (Pa s)

$\rho \quad$ Density $\left(\mathrm{kg} \mathrm{m}^{-3}\right)$

$\tau \quad$ Characteristic time (s)

\section{Subscripts}

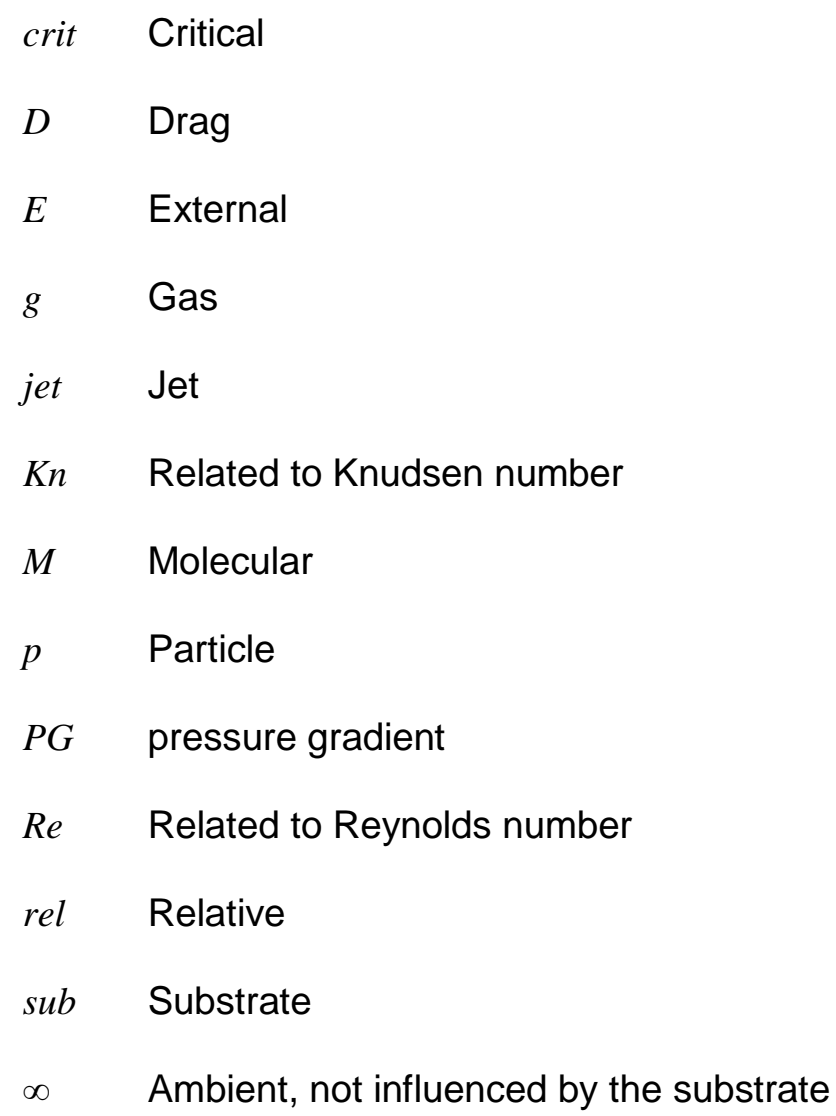

\section{Symbols}

First derivation with respect to time

Second derivation with respect to time

Corrected 


\section{Introduction}

Inspired by the columnar structured strain tolerant thermal barrier coatings (TBCs) which are produced by Electron Beam-Physical Vapor Deposition (EB-PVD), suspension plasma spraying (SPS) and plasma spray-physical vapor deposition (PS-PVD) are implemented as alternatives to manufacture similar microstructures (Ref 1-3). Investigations on the properties and performance as well as on the influence of process parameters on the formation of that kind of columnar TBCs can be found elsewhere (Ref 4-10). Additionally, aerosol deposition $(A D)$, sometimes referred to as vacuum kinetic spray (VKS) or vacuum cold spray (VCS), is a novel process (Ref 11) featuring high-kinetic and low-pressure conditions as well as small feedstock particles like SPS and PS-PVD. However, microstructures are typically rather dense and homogeneous.

If the feedstock particles are sufficiently small, due to their limited inertia they can follow the gas flow in the free working gas jet as well as in the boundary layer (BL) attached to the substrate. The substrate exerts a strong impact on the velocity and temperature field in the gas flow (Ref 12). A flow perpendicular to the surface of the substrate stagnates near the point of impact and is deflected in the direction parallel to the substrate surface. As a consequence, small particles can either be carried away by the gas and thus do not participate in the coating build-up or create defects since they tend to impact on the flanks of surface asperities. Since the formation of the flow around the substrate is dependent on the overall substrate shape (e.g. flat or cylindrical), this has a significant effect on the particle deposition (Ref 13).

Van Every et al. (Ref 14) described the effect of different relations of drag and inertial forces as a function of the particle size. Depositing very small particles, peaks initially grow mainly in the lateral direction on the flanks of surface protrusions (referred to as 'roots' in (Ref 15,16)) so that the inter-deposit gaps are closed. As deposition proceeds, the evolution becomes competitive since smaller asperities are shadowed by larger ones. The ongoing vertical 
growth results in the formation of characteristic tapered columns. Also increasing the particle size creates convergent porosity bands between surface asperities. Beyond a specific particle diameter, uniform thickness is obtained which covers the surface profile with a homogeneous coating. For specific working gas jet parameters such as temperature, pressure, and velocity, this particular particle size depends on the substrate roughness. Racek (Ref 17) described the formation of large columnar stacking defects if the substrate surface roughness is significantly higher than the average diameter of the impacting particles. This ratio can be used to achieve the best mechanical coating adhesion (Ref 18,19).

At high particle velocities, splashing of the molten particles can play an additional role resulting in splat fragmentation, rebounding, and deposition of sub-splatsized particles on the flanks of surface protrusions. Such speckles grow progressively with coating deposition forming approximately conical volumes with highly porous bands passing through. The effect is reduced on convex shaped substrates (Ref 17). Plasma fluctuations may contribute to the formation of such stacking defects (Ref 20).

An experimentally based process map illustrates systematically distinct microstructure evolution zones at different torch operating conditions combining effects of suspension fragmentation in the plume and melting regimes was proposed by Seshadri et al. (Ref 21). The substrate roughness was found to have a strong impact on column morphology. Microstructures of SPS coating can be tailored from vertically cracked to columnar structured by increasing the surface roughness (Ref 22). On smooth surfaces, columns were found to become larger and their size to be more dispersed (Ref 23). Such a loss of organization between columns, as well as the increase in column sizes, induced a loss of compliance under thermal stresses (Ref 24) so that the strain tolerance essential for TBCs was affected. 
The deposition of columnar structured TBCs on complex shaped, real turbine parts like vanes was reported ibid. as well. Off-normal spray angles were identified to be a relevant issue as they often cannot be avoided, e.g., if the torch cannot be aligned in normal direction to the substrate surface due to short spray distances. The consequences are inhomogeneous coating thickness and columnar structures which are not well-defined.

It is evident that the coating microstructure and in particular the formation of columnar structures is strongly determined by the development of the particle trajectories close to the substrate. The numerical study of the SPS process performed by Farrokhpanah et al. (Ref 25) gives examples for the distributions of normal and tangential impact velocity components (and thus impact angles) depending on process parameters like torch power and plasma gas flow. Oberste Berghaus et al. (Ref 26) demonstrated by simplified simulations the influence of particle size and material on the normal velocity and thus the evolution of the trajectories through the BL. Monte Carlo simulations by Wang et al. (Ref 27) showed that the distribution of the particle impact angles significantly influences the shape, inclination, and porosity of the columns. These findings were obtained with regard to the PSPVD process, but are principally valid for other spray processes.

To further investigate the interaction between gas and particles in the $\mathrm{BL}$ attached to the substrate, numerical studies were performed in the present work considering typical conditions for SPS, PS-PVD, and AD. As partially low pressures and/or high velocities occur, particular importance is placed on rarefaction and compressibility effects on the drag force. Rarefaction can become significant if the feedstock particles are small and the working gas is under very low pressure (100 to $200 \mathrm{~Pa}$ ) and compressibility in case of high velocities. The corresponding correction factors calculated in this work showing the significance of these effects. Thus, they can be a guideline to choose appropriate modeling approaches for these novel spraying processes. Furthermore, Stokes numbers were calculated which represent the ratio of the characteristic times for directional changes of the gas flow and of the particle 
response. The results shed light on the formation of microstructures and the disposition to generate columnar structures or stacking effects. This can support the selective optimization of feedstock and process parameters.

\section{Theoretical Background}

\section{Momentum Transfer}

The acceleration and thus the trajectory of a particle suspended in a moving fluid results from the momentum transfer from the flow. The particle acceleration $\dot{v}_{p}$ can be described on the basis of the equilibrium of the inertial force with the sum of the external forces acting on it according to the simplified form of the Basset-Boussinesq-Oseen equation (Ref 28)

$$
v_{p} m_{P}=F_{D}+F_{P G}+F_{E}
$$

where $v_{p}$ is the particle velocity, the dot indicates the derivation with respect to time, $m_{p}$ is the particle mass, $F_{D}$ is the drag force, $F_{P G}$ is the force due to a pressure gradient, and $F_{E}$ are external potential forces (e. g. gravity, electric or magnetic forces). In this work, it is assumed that the latter two forces are not relevant due to the very small particle diameters. Furthermore, thermophoretic effects as well as particle ablation or evaporation are neglected for simplification. For spherical particles, the drag force can be written as

$$
F_{D}=\frac{\pi}{8} d_{P}^{2} \rho_{g} v_{r e l}^{2} C_{D}
$$

where $d_{p}$ is the particle diameter, $\rho_{g}$ is the density of the gas, $v_{r e l}$ is the relative velocity between gas and particle, and $C_{D}$ is the dimensionless drag coefficient. $C_{D}$ is strongly dependent on the particle Reynolds number

$$
R e_{p}=\frac{\rho_{g}\left|v_{r e l}\right| d_{p}}{\mu_{g}}
$$

where $\mu_{g}$ is the dynamic viscosity of the gas. For small Reynolds numbers $R e_{p}<0.2$, there is pure Stokesian motion (creeping flow) and $C_{D}$ can be expressed by

$$
C_{D}=\frac{24}{R e_{p}}
$$


There are several semi-empirical approaches for correction factors $f_{R e}$ to $C_{D}$ in order to cover higher $R e_{p}$ number regimes. In this work, an expression according to Schiller and Naumann (Ref 29) is used

$$
f_{R e}=1+0.15 R e_{p}^{0.687}
$$

which can be applied for $R e_{p}<800$. Figure 1 compares experimental data with this and other approaches.

\section{Compressibility and Rarefaction Effects}

The compressibility of a fluid can become important at high relative particle velocities compared with the gas specific sonic speed (Ref 30), which is $c=\sqrt{\gamma R T_{g}}$ for ideal gases, where $\gamma$ is the specific heat capacity ratio of the gas, $R$ is the specific gas constant, and $T_{g}$ is the gas temperature. Such effects can increase the drag force which is exerted by the fluid on suspended particles. In this regard, the relevance of compressibility can be assessed by means of the particle Mach number

$$
M a_{p}=\frac{\left|v_{r e l}\right|}{\mathrm{c}}
$$

Rarefaction effects occur if continuum flow conditions around a particle are not valid anymore because the fluid density is low and the energy exchange between particle and fluid molecules is only small. This can be assessed considering the particle Knudsen number

$$
K n_{p}=\frac{\lambda}{d_{p}}
$$

where $\lambda$ is the mean free path length of the surrounding gas molecules. Applying the model of a hard-sphere with a specific diameter and the same viscosity as the actual gas, $\lambda$ can be expressed by (Ref 31)

$$
\lambda=\frac{\mu_{g}}{p} \sqrt{\frac{\pi k_{B} T_{g}}{2 m_{M}}}
$$

where $p$ is the local pressure, $k_{B}$ is the Boltzmann constant, and $m_{M}$ the absolute molecular mass. For an ideal gas, $K n_{p}$ can be written also in terms of $R e_{p}$ and $M a_{p}$ 


$$
K n_{p}=\frac{M a_{p}}{R e_{p}} \sqrt{\frac{\pi \gamma}{2}}
$$

The continuum criterion is $K n_{p} \ll 1$ (Ref 30). Different regimes of $K n_{p}$ can be distinguished as follows (Ref 32):

- Continuum flow $\left(10^{-3}>K n_{p}\right)$,

- $\quad$ Slip flow $\left(10^{-3}<K n_{p}<10^{-1}\right)$,

- Transition flow $\left(10^{-1}<K n_{p}<10\right)$, and

- Free-molecular flow $\left(10<K n_{p}\right)$.

Only if $K n_{p}$ is very small $\left(K n_{p} \ll 0.1\right)$ the continuum approaches used in fluid mechanics and heat transfer approaches with continuous boundary conditions can be applied. At high Knudsen numbers, however, corrections are required to consider the Knudsen or rarefaction effect on the plasma-particle interaction. This effect may significantly reduce the drag force (Ref 33) as well as the heat transfer (Ref 34) experienced by particles moving in a gas flow because the exchange of kinetic and thermal energy between particles and gas molecules by collisions is very low.

At very high Reynolds numbers $\left(R e_{p}>>1\right)$, the conditions are dominated by compressibility as the Knudsen numbers are generally small. In contrast, at very low Reynolds numbers, the physics tend to be dominated by rarefaction as the Mach numbers are generally small here (Ref 30). Both regimes are linked by a nexus at $R e_{p}=45$ where $C_{D} \approx 1.63$ independent of $M a_{p}$ and $K n_{p}$. Figure 2 shows these two regimes of the drag coefficient $C_{D}$ as a function of the particle Reynolds number $R e_{p}$. The principal effects of rarefaction and compressibility of the fluid on the drag acting on suspended particles are apparent.

The conditions investigated in this work comprise the rarefaction-dominated regime only (left hand part of Figure 2) since the Reynolds numbers are generally very small due to the small particle sizes. For such conditions, a slip correction factor $f_{K n}$ can be applied to the drag coefficient $C_{D}$. In the context of thermal spraying, slip effects were discussed by Chyou 
(Ref 35) and Pfender (Ref 32). Their correction factors are valid in the range of $10^{-2}<K n<1$. However, under the conditions of this work, considerably higher Knudsen numbers occur. Several other researchers investigated slip correction, for the free molecular flow regime $\left(K n_{p} \geq 10\right)$ and for different gas species (Ref 36,37$)$, using the form initially proposed by Cunningham (Ref 38)

$$
f_{K n}=\left[1+K n_{p}\left(\alpha+\beta \exp \left(-\delta / K n_{p}\right)\right)\right]^{-1}
$$

where $\alpha, \beta$, and $\delta$ are parameters which are adjusted to fit experimental data. (It should be noted that in some works the Knudsen number is based on the particle radius instead of the diameter; this affects the values of these parameters.)

For the case of free molecular flow, $f_{K n}$ approaches an asymptotic function which can be obtained with the parameters $\alpha+\beta=3.296$ and $\delta=0$ (Ref 37); this is in good agreement with earlier findings, e.g. of Epstein (1929) in (Ref 30) and Rader (Ref 36). For the transition regime $\left(10<K n_{p} \leq 0.1\right)$, the parameters $\alpha=2.514, \beta=0.8$, and $\delta=0.55$ can be used according to Clift (1978) in (Ref 30); these are similar values as reported in (Ref 36).

As long as the particle Mach numbers do not become significant, i.e. of order unity or more, the Stokes and slip correction factors can be combined to calculate a modified drag coefficient (Ref 30)

$$
C_{D}^{\prime}=C_{D} f_{R e} f_{K n}
$$

An expression for the overall fit to the rarefaction-dominated regime simultaneously allowing for Reynolds, Knudsen, and Mach effects with a validity range of $R e_{p} \leq 45$ can be found ibid.

\section{Characteristic Times}

The momentum transfer from the fluid to the suspended particles as well as the direction change of the flow due to external impacts, e.g. obstacles, can be characterized by different characteristic times. Their ratio constitutes the dimensionless Stokes number St. Generally, if 
$S t \gg>1$, particles are dominated by their inertia and tend to detach from the flow; for $S t<<1$, particles are likely to follow the fluid closely, i. e. particle trajectories and fluid streamlines are almost coincident.

Neglecting $F_{P G}$ and $F_{E}$, Eqs. 1-4 can be combined to form a first order ordinary differential equation. The solution gives the particle velocity as a function of time

$$
v_{p}(t)=v_{g}\left(1-\exp \left(-t / \tau_{p}\right)\right)
$$

where $v_{g}$ is the gas velocity. The characteristic time for momentum transfer (particle relaxation time) (Ref 39$)$ is

$$
\tau_{p}=\frac{\rho_{p} d_{p}^{2}}{18 \mu_{g}}
$$

The characteristic time for the change of the gas flow direction due to external influences is

$$
\tau_{g}=\frac{v_{g}}{v_{g}}=\frac{1}{v_{g} \kappa_{g}}
$$

where the $\dot{v}_{g}=v_{g}^{2} \kappa_{g}$ is the local acceleration perpendicular to the streamline (centripetal acceleration which acts on the particle by the fluid if the flow changes direction) and $\kappa_{g}$ is the local curvature of the streamline. Taking an axisymmetric flow as a basis with streamlines in the radial-axial coordinate system $(r, z)$, the local curvature of the stream line is obtained by

$$
\kappa_{g}=\left|\frac{\dot{r} \ddot{z}-\ddot{r} \dot{z}}{\left(\dot{r}^{2}+\dot{z}^{2}\right)^{3 / 2}}\right|
$$

The dots indicate the first and second derivation with respect to time. $\dot{r}$ and $\dot{z}$ are given directly by the velocity field of the BL. The accelerations $\ddot{r}$ and $\ddot{z}$ can be numerically approximated by finite difference quotients.

The dimensionless Stokes number $S t$ is then obtained by relating $\tau_{p}$ to the time scale $\tau_{g}$

$$
S t=\frac{\tau_{p}}{\tau_{g}}
$$

As mentioned above, the two general cases of $S t>>1$ and $S t<<1$ are distinguished. A more accurate criterion provided by the concept of critical Stokes numbers below which inertial 
deposition does not occur, Taylor (1940) in (Ref 40). If St is larger than a particular critical value $S t_{\text {crit }}$ (see Equ. 17 below), particles are always deposited on the substrate within a finite time. However, if St is smaller, they just may reach the substrate, depending on the initial conditions. Particles initially moving with the flow a long distance away from the substrate are not deposited, but approach the surface asymptotically at large times if the substrate is sufficiently large. For the case of an axisymmetric flow normal to a round disk with diameter $d_{\text {sub }}$, the critical Stokes number is calculated by (Ref 40$)$

$$
S t_{\text {crit }}=\frac{\pi}{4}\left(\frac{1}{4}+\frac{\pi^{2}}{\left[\ln \left(0.7132 \operatorname{Re}_{\text {sub }}\right)\right]^{2}}\right)
$$

with the Reynolds number related to the substrate

$$
R e_{s u b}=\frac{v_{g, \infty} \rho_{g, \infty} d_{s u b} / 2}{2 \mu_{g, \infty}}
$$

where $v_{g, \infty}$ is the velocity, $\rho_{g, \infty}$ the density, and $\mu_{g, \infty}$ the dynamic viscosity of the gas far away from the substrate; the substrate disk radius $d_{\text {sub }} / 2$ is taken as the characteristic length to define the scale of the system.

In case of Reynolds and Knudsen effects, the particle relaxation time $\tau_{p}$, and thus the Stokes number $S t$, can be corrected directly by applying the corresponding correction factors $f_{R e}$ and $f_{K n}$ given in Eqs. 5 and 10

$$
S t^{\prime}=S t / f_{R e} f_{K n}
$$

\section{Calculation Model}

\section{Gas Flow Streamlines}

The flow model considers an axisymmetric flow normal to a plate (substrate). The potential flow far from the substrate is assumed to be frictionless (non-viscous). In the BL however, the viscosity must be considered to fulfill the non-slip condition at the substrate surface. Analogous to the velocity $B L$, there is a temperature $B L$ adjacent to the substrate surface due to convective heat transfer. On the basis of the Prandtl number $\mathrm{Pr}$, it was estimated that the same BL thicknesses for friction as well as for convection can be applied for typical 
conditions in thermal spray processes. The ratio of temperature and velocity boundary layers is approximately proportional to $\operatorname{Pr}^{-1 / 3}$ (Ref 41 ). The shape of the temperature profile between the top of the $B L$ and the substrate surface was assumed to be parabolic.

The thickness of the $\mathrm{BL}$ and the two dimensional velocity field inside in radial and axial direction $r$ and $z$ were calculated each by applying tabulated solutions of the Navier-Stokes equation given in (Ref 42) for the case of an axisymmetric flow normal to a plate (substrate). This is shown schematically in Figure 3. A detailed description of this approach and solution can be found in a previous paper (Ref 43 ).

For the special case of an highly under-expanded jet impinging on the substrate at short distance from the nozzle where it is still supersonic, a normal shock disk reveals a region of separated flow surrounding the stagnation point on the jet axis (Ref 44). In the subsonic bubble behind the disk, the flow is redirected radially towards the center so that a circulation is formed. This was shown to be relevant for cold gas spraying (Ref 45). Regarding the spray processes investigated in this work, something similar could be expected also for $A D$, however only in the immediate area surrounding the jet axis since the jet diameter is small compared to the other investigated processes. Such effects are not considered in the present approach. In the PS-PVD process, the jet is already subsonic when reaching the substrate. In (Ref 46), an example for an PS-PVD jet is given. SPS conditions are generally subsonic.

With the help of this model, discrete streamlines were calculated applying a simple numerical integration scheme and setting a specific inflow velocity into the BL. The streamlines were obtained as a sequence of $(r, z)$ data points in a stepwise manner by multiplication of the local gas velocities (given by the velocity field in the $\mathrm{BL}$ ) with small time increments being $10^{-8} \mathrm{~s}$ or less. This had to be done for the vectors in the radial and axial direction $r$ and $z$, respectively. The starting point is located at the BL margin. In this work the radial distance from the jet axis was $1 \mathrm{~mm}$. This distance is taken as an example; any other radial offset is 
possible. The end point for the calculation of streamlines is a radial distance of $r=60 \mathrm{~mm}$ from the jet axis. The densities, dynamic viscosities, sonic speeds, and specific heat ratios were calculated depending on the local temperatures using fitted data obtained by means of the CEA2 code (Ref 47,48) taking into account the pressures and hot gas compositions (considering ionization where applicable).

\section{Particle Trajectories}

The particle motion was calculated on the basis of the particle acceleration which was obtained combining Eqs. 1-4 and applying the correction factors $f_{R e}$ and $f_{K n}$ given in Eqs. 5 and 10. Particle velocities and positions between entering the $B L$ and impact the substrate at $z=0$ were obtained stepwise proceeding in discrete time increments. The same numerical integration scheme was applied as used for the streamlines, however integration had to be performed twice, as the particle acceleration $v_{p}$ (Eq. 1) is the starting point which is the second derivation of the particle position with respect to time. Stringing all the calculated particle positions, the particle trajectories were obtained. Figure 3 shows schematically the boundary layer flow model with plasma gas streamlines and particle trajectories.

\section{Process Parameters and Conditions}

The plasma and working gas parameters, respectively, given in Table 1 were taken as a basis for the calculations. The plasma conditions were taken from the references as mentioned in Table 2. The APS parameters were applied for SPS investigated in this work. Substrate temperatures were estimated on the basis of pyrometric measurements performed by the author in experiments with similar plasma powers and stand-off distances. 
Table 1: Plasma and working gas parameters.

\begin{tabular}{|l|l|l|r|r|r|}
\hline Case ID & $\begin{array}{l}\text { Nozzle } \\
\text { diameter, } \\
\mathrm{mm}\end{array}$ & $\begin{array}{l}\text { Plasma/working } \\
\text { gas, slpm* }\end{array}$ & Current, A & $\begin{array}{l}\text { Power, } \\
\mathrm{kW}\end{array}$ & $\begin{array}{l}\text { Pressure, } \\
\mathrm{Pa}\end{array}$ \\
\hline SPS-1 & 6 & $37 \mathrm{~N}_{2} / 27 \mathrm{H}_{2}$ & 290 & 29 & $10^{5}$ \\
\hline SPS-2 & 8 & $75 \mathrm{Ar} / 25 \mathrm{H}_{2}$ & 290 & 29 & $10^{5}$ \\
\hline PS-PVD & 12.5 & $35 \mathrm{Ar} / 60 \mathrm{He}$ & 2,600 & 119 & 200 \\
\hline AD & 2.3 & $15 \mathrm{Ar}$ & - & - & 300 \\
\hline
\end{tabular}

* slpm = standard liters per minute

For $A D$, the nozzle diameter is an equivalent diameter of a slit nozzle since only axisymmetric conditions were considered in this work. The gas temperature of $200 \mathrm{~K}$ was estimated by a one-dimensional calculation of the expansion through the nozzle. Thus, this is the temperature in the flow and not a stagnation temperature. As mentioned above, shock disks and stagnation bubbles were not considered. Thus, it was reasonable to assume the flow temperature.

Table 2: Jet conditions and substrate temperatures.

\begin{tabular}{|c|c|c|c|c|c|}
\hline Case ID & $\begin{array}{l}\text { Spray dist., } \\
\text { mm }\end{array}$ & $\begin{array}{l}\mathrm{T}_{\text {jet }} \\
\text { on axis, } \mathrm{K}\end{array}$ & $\begin{array}{l}\mathrm{T}_{\text {sub. }} \\
\text { on axis, } \mathrm{K}\end{array}$ & $\mathrm{v}_{\text {jet }}, \mathrm{m} \mathrm{s}^{-1}$ & Ref. \\
\hline \multirow{2}{*}{ SPS-1 } & 60 & 4,400 & 720 & 280 & \multirow{2}{*}{ (Ref 49) } \\
\hline & 100 & 2,700 & 520 & 180 & \\
\hline \multirow{2}{*}{ SPS-2 } & 60 & 4,300 & 670 & 250 & \multirow{2}{*}{ (Ref 49) } \\
\hline & 100 & 2,400 & 470 & 155 & \\
\hline PS-PVD & 1000 & 4,275 & 1,250 & 1,400 & (Ref 50) \\
\hline$A D$ & 10 & 200 & 200 & 500 & $\begin{array}{l}\text { typical } \\
\text { after } \\
\text { (Ref 11) }\end{array}$ \\
\hline
\end{tabular}

For each calculated case, three particle diameters were applied covering the typical range for the investigated spray processes (Ref 18). The particle density was set to $6.07 \cdot 10^{3} \mathrm{~kg} / \mathrm{m}^{3}$ corresponding to partially yttria stabilized zirconia (YSZ). For SPS, the impacting liquid splats 
are formed by agglomeration and melting of nano-sized solid particles injected with the suspension into the plasma jet. Here, typical particle diameters were estimated to be $1.0,0.5$, and $0.2 \mu \mathrm{m}$ (Ref 39). For PS-PVD, particle diameters were estimated to be $1 \mathrm{~nm}, 4 \mathrm{~nm}$, and $10 \mathrm{~nm}$, corresponding approximately to 15,1000 , and 15000 zirconia molecules. Thus, the size range of clusters is covered which could nucleate homogeneously and grow under highly supersaturated conditions in the BL attached to the substrate. Single vapor molecules were assumed to follow the plasma gas flow and were not considered here. For AD, particle diameters of $0.2 \mu \mathrm{m}, 1 \mu \mathrm{m}$, and $5 \mu \mathrm{m}$ were assumed. Here, it is difficult to estimate the working gas and substrate temperatures. Calculating the adiabatic and isentropic expansion of $\mathrm{Ar}$ at room temperature into a chamber with $300 \mathrm{~Pa}$, a deep temperature drop below $50 \mathrm{~K}$ is obtained. However, convection and mixing with ambient gas was not considered. Thus, $200 \mathrm{~K}$ was roughly estimated to be the temperature of the working gas and the substrate. In future work, this must be examined more precisely since the working gas might exhibit considerable changes of its characteristics at lower temperatures.

To avoid the stagnation point on the sample surface, where the particles would not receive any radial momentum, they were assumed to start their trajectories through the $\mathrm{BL}$ at a radial position of $1 \mathrm{~mm}$ off the jet axis. Furthermore, as they are small, it was presumed that they enter the BL with the same velocity as the gas flow.

\section{Results}

\section{Boundary Layer}

As mentioned above, the calculation domain is the $\mathrm{BL}$ within a radius of $60 \mathrm{~mm}$ around the jet axis. Table 3 gives the BL characteristics for the investigated cases. The calculation of the thickness is described in a previous paper (Ref 43). The viscosity data are averaged over the BL thickness. 
Table 3: Characteristics of the boundary layers; the viscosities are averaged over the BL thickness.

\begin{tabular}{|l|r|l|l|}
\hline \multirow{2}{*}{ Case ID } & $\begin{array}{l}\text { Spray distance, } \\
\mathrm{mm}\end{array}$ & $\begin{array}{l}\text { Thickness, } \\
\mathrm{mm}\end{array}$ & $\begin{array}{l}\text { Kinematic } \\
\text { viscosity, } \\
\mathrm{m}^{2} \mathrm{~s}^{-1}\end{array}$ \\
\hline \multirow{2}{*}{ SPS-1 } & 60 & 0.18 & $1.2510^{-3}$ \\
\cline { 2 - 4 } & 100 & 0.15 & $5.3010^{-4}$ \\
\hline SPS-2 & 60 & 0.16 & $8.9110^{-4}$ \\
\cline { 2 - 4 } & 100 & 0.13 & $3.3710^{-4}$ \\
\hline PS-PVD & 1000 & 5.86 & $7.6210^{-1}$ \\
\hline AD & 10 & 0.19 & $2.3210^{-3}$ \\
\hline
\end{tabular}

The comparison of the SPS data shows that the kinematic viscosity and thus the BL thickness are slightly higher for $\mathrm{N}_{2} / \mathrm{H}_{2}$ than for $\mathrm{Ar} / \mathrm{H}_{2}$. By decreasing the spray distance, the viscosity, BL thickness, and temperature increase. For PS-PVD, the values are significantly larger due to much higher temperatures and lower densities. For AD, the low temperature and thus small dynamic viscosity compensates for the increasing effect of low density on BL thickness and on the kinematic viscosity.

\section{Drag Coefficients}

Figure 4 shows the development of the drag coefficients as a function of particle Reynolds numbers calculated along the particle trajectories from entering the $B L$ until impact on the substrate surface for particles with three different diameters; the process conditions were SPS-1 at $60 \mathrm{~mm}$ spray distance. This diagram corresponds to the left hand part of the plot in Figure 2, however with the $\left(C_{D}{ }^{\prime}, R e_{p}\right)$ data as calculated along the particle trajectories according to Eqs. (3) and (11), respectively. The black lines are contour lines for constant Knudsen numbers, the black dash-dotted line indicates the extreme case as $K n_{p}$ and $M a_{p}$ approach zero. 
The highest particle Reynolds number was found to be approximately 2.6 for the largest particle shortly before impact on the substrate. Thus, the corresponding maximum correction factor $f_{R e}$ for the drag coefficient $C_{D}$ is 1.29 which is not that relevant.

The particle Knudsen numbers indicate transition flow conditions so that rarefaction must not be neglected. This was already reported for SPS in (Ref 39). Rarefaction has the largest effect on the smallest particles when entering the BL where the temperature and hence the mean free path are largest. Here, the drag coefficient $C_{D}$ has to be reduced by a factor of $f_{K n}=0.03$. Close to the substrate, this reduction becomes less as $f_{K n}$ increases to 0.22 .

The highest particle Mach numbers are between 0.39 and 0.41 for all investigated particle diameters. According to (Ref 30), compressibility does not affect the drag coefficients significantly. These maximum particle Mach numbers are observed shortly before impact on the substrate where the relative velocity between fluid and particle is highest as the BL sticks to the substrate surface.

The drag coefficients for the SPS-2 conditions with the different plasma gas mixture at $60 \mathrm{~mm}$ spray distance (not shown) do not reveal any significant differences. Figure 5 illustrates for the SPS-1 case that at larger spray distances the rarefaction effects are smaller. Here, the largest correction of the drag coefficient $C_{D}$ has to be applied for the smallest particle when entering the $\mathrm{BL}$ by a factor of $f_{K n}=0.06$. This is due to the lower temperature compared to $60 \mathrm{~mm}$ spray distance. Hence, the mean free path in the fluid and thus the particle Knudsen numbers are smaller.

Figure 6 gives the corresponding diagram for the PS-PVD cases. The particle Reynolds numbers are considerably smaller compared to SPS since the particles are tiny and the kinematic viscosity in the $\mathrm{BL}$ is three orders of magnitudes higher. Hence, there is no need for correction of the drag coefficient $C_{D}$ as $f_{R e}$ approaches unity. 
Since the mean free path is very high due to the high temperature and low pressure while the particles are very small, the particle Knudsen numbers become large indicating free molecular flow (Ref 51). Thus, the strong rarefaction effect demands considerable correction of the drag coefficient $C_{D}$. They are largest for the smallest particles when entering the BL. Here, a factor of $8.7 \cdot 10^{-7}$ was found applying the asymptotic function for $f_{K n}$ (Eq. 10).

The maximum particle Mach number was 1.85 for the largest particle shortly before impact on the substrate. This indicates the onset of compressibility effects. The corresponding maximum correction factor for the drag coefficient $C_{D}$ would be 1.72 which, however, was neglected in this work with regard to the large corrections for rarefaction effects.

Figure 7 gives the drag coefficients for the three particle diameters considered under AD conditions. The particle Reynold numbers are in a similar range like under SPS conditions. Thus, the corresponding maximum correction factor $f_{R e}$ for the drag coefficient $C_{D}$ is not appreciable. However the rarefaction effect is larger and thus, must not be neglected. For the smallest particle with $0.2 \mu \mathrm{m}, f_{K n}$ decreases to 0.003 . Moreover, the particles pass the onset of compressibility effect short before impacting the substrate. Similar to PS-PVD, the maximum particle Mach number reaches 1.89 .

\section{Stokes numbers}

Applying the drag coefficients $C_{D}$ ' corrected according to Eq. 11, the particle trajectories could be calculated. Considering the local characteristic times for particle relaxation $\tau_{p}$ and for change of the gas flow direction $\tau_{g}$, the developments of the Stokes numbers $S t$ ' were calculated along the particle trajectories (Eqs. 16, 19). Figure 8 shows this data for the case SPS-1: $60 \mathrm{~mm}$, plotted against the $z$ coordinate normal to the substrate. It is obvious that for parts of the trajectories the Stokes numbers are smaller than or slightly above $S t_{c r i t}$. This means that the particle trajectories are almost coincident with the stream lines of the fluid as 
also shown in the simulations of Jadidi et al. (Ref 52). However, for the larger particles the Stokes numbers are above $S t_{c r i t}$ indicating that trajectories and streamlines diverge. Generally, when approaching the substrate, the characteristic time for the direction change of the flow $\tau_{g}$ increases by approximately one order of magnitude while the particle relaxation time (corrected for rarefaction effect) $\tau_{p}{ }^{\prime}$ decreases just slightly.

Increasing the spray distance to $100 \mathrm{~mm}$ leads to a general slight decrease of the Stokes numbers (not shown) because the characteristic times for the change of the flow direction $\tau_{g}$ are higher while the particle relaxation times $\tau_{p}$ ' are hardly changed. The same trend was observed by Jadidi et al. (Ref 53) for suspension HVOF, however more pronounced. Similar effects on $\tau_{g}$ and $\tau_{p}$ ' are obtained if the plasma gas mixture is changed from SPS-1 to SPS-2 conditions (not shown). The critical Stokes numbers $S t_{c r i t}$ are very similar for all SPS cases.

Figure 9 gives the corresponding diagram for the PS-PVD conditions. The Stokes numbers are generally higher due to large rarefaction effects so that the particle relaxation time (corrected for rarefaction effect) $\tau_{p}$ ' is increased although the particle diameters are very small. St predominantly exceeds the critical value $S t_{c r i t}$. However, it must be noted that the particles still grow by condensation and coalescence only when passing the BL. This was not considered in this simplified model. Thus, the Stokes numbers are initially overestimated.

Furthermore, the characteristics of the developments are different as the Stokes numbers increase when approaching the substrate under PS-PVD conditions while they decrease in the SPS cases. This is due to higher characteristic times for flow direction changes $\tau_{g}$ when entering the BL. Here, the stream lines are less curved since the BL in PS-PVD is much thicker than the BL under SPS conditions.

The Stokes numbers for the AD cases given in Figure 10 were the largest found in this work. Compared to SPS with the smallest Stokes numbers, the curvature of the flow lines is 
sharper leading to smaller characteristic times for the direction change of the fluid $\tau_{g}$; on the other hand, the particle's characteristic times for momentum transfer $\tau_{p}$ ' are significantly larger than under SPS conditions as the dynamic viscosity is distinctly lower.

\section{Discussion}

On the basis of the calculated Stokes numbers, it can be expected that the direction of particle impact on the substrate under the investigated SPS conditions generally deviates from the substrate surface normal because the particles are highly diverted by the gas flow which turns parallel to the surface as can be seen in the plasma gas stream lines in Figure 3. It is only natural that the Stokes numbers of the larger particles are higher due to their inertia. Increasing the spray distance and changing the plasma gas mixture from $\mathrm{N}_{2} / \mathrm{H}_{2}$ to $\mathrm{Ar} / \mathrm{H}_{2}$ while maintaining the electrical input power leads to smaller Stokes numbers and thus more deflection of the particle trajectories. With respect to the substrate plane, the steepest trajectories thus can be expected for the SPS-1 conditions at $60 \mathrm{~mm}$, and the shallowest ones for the SPS-2 condition at $100 \mathrm{~mm}$ spray distance.

It is suggested that the shallow particle impact leads to a strong development of the deposited columns in the lateral direction. Consequently, the columns develop a tapered shape so that the growth becomes competitive and only a few columns can further develop. Thus, the gaps between the columns are closed and a rather dense coating microstructure is formed. These are typical characteristics of columnar structured TBCs manufactured by SPS (Ref 4,6-8,24). Zhou et al. (Ref 9) showed that at an increased spray distance of $100 \mathrm{~mm}$, microstructures with fine columns were generated even on smooth surfaces $\left(R_{a}=0.06 \mu \mathrm{m}\right.$, $\left.R_{a}=0.26 \mu \mathrm{m}\right)$. At the same relatively long spray distance, the smallest Stokes numbers were found in this work.

Under PS-PVD conditions, the Stokes numbers for nano-sized clusters and non-evaporated feedstock particles of the investigated sizes are generally larger than for the particles under 
SPS conditions. This is a consequence of considerable slip effects as indicated by the large particle Knudsen numbers. Hence, it is expected that the particle trajectories at impact on the substrate are steeper with respect to the substrate surface under PS-PVD conditions than for SPS. However, as already mentioned above, the simplified model used in this work does not consider that in PS-PVD the particles grow from small nuclei only when passing through the BL. Thus, they initially follow the gas stream lines very closely so that the final impact directions should be less inclined with respect to the substrate surface than calculated here.

As it is known that considerable feedstock fractions are evaporated in the PS-PVD process (Ref 51,54), it is suggested that these vapor molecules follow the plasma gas stream lines and are diverted parallel to the substrate surface. Thus, larger nano-sized clusters could be separated from vapor molecules. While the former preferably impact on top of the columns, the latter can reach the column flanks. This could lead to the typical open columnar microstructures with wide gaps in-between and to the featherlike inner structure of the columns (Ref 50,55).

Monte Carlo simulations by Wang et al. (Ref 27) recently revealed that the width of the impact angle distribution considerably affects the column forms. A wider distribution leads to tapered, compact shapes while narrow distributions result in thin, long, and fingerlike columns with wider gaps. Since the former structure is typical for SPS coatings and the latter is more PS-PVD-like, it can be concluded that PS-PVD is generally a more directional process than SPS as indicated by the larger Stokes numbers.

The calculations for the AD process revealed the highest Stokes numbers. Hence, particle trajectories can be expected to be hardly affected by the diverting working gas flow in the boundary layer so that they impinge on the substrate more or less in parallel with the jet axis. This in agreement with the dense and defect-free microstructures which are frequently reported for AD coatings (Ref 11). 


\section{Summary}

An analytical calculation model for plasma gas streamlines and particle trajectories was developed. The calculations were performed for an axisymmetric flow onto a flat substrate under typical SPS, PS-PVD, and AD conditions and for three particle sizes in each case. Particular consideration was given to rarefaction and compressibility effects as they can be significant for these novel spray processes.

Figure 11 gives an overview on the value domains of the Reynolds correction factor $f_{R e}$ found for the different spray processes and three typical particle sizes in each case. It is apparent, that the correction of the drag coefficient by $f_{R e}$ must not be neglected for larger particles under SPS conditions. Figure 12 summarizes the calculated slip correction factors $f_{K n}$. For SPS it was found that rarefaction must not be neglected while compressibility is not significant. For PS-PVD, rarefaction leads to very large slip effects. It might be that the applied theory becomes uncertain at such high Knudsen numbers. Compressibility becomes relevant near by the substrate. Also for the AD process, rarefaction effects were found to be considerable; like in PS-PVD, compressibility becomes significant just initially.

On this basis, the developments of Stokes numbers St' were calculated along particle trajectories. Figure 13 shows the value domains of the results. For SPS, the disposition to form columnar structures and stacking errors increases with decreasing particle diameter since the values fall further below the critical Stokes number $S t_{c r i t}$. Regarding PS-PVD, it was mentioned already that the Stokes numbers are probably overestimated. As the largest Stokes numbers were found for $A D$ conditions, it can be expected that the particles do not follow the streamlines and impinge more or less in normal direction on the substrate surface. 
These findings shed light on principal differences between the investigated spray processes and the formation mechanisms of microstructures. They are in basically good agreement with experimental and modelling results reported in the literature.

\section{References}

1. H. Kaßner, R. Siegert, D. Hathiramani, R. Vaßen, D. Stöver, Application of Suspension Plasma Spraying (SPS) for Manufacture of Ceramic Coatings, J. Therm. Spray Technol., 17(1), 115-123 (2008)

2. R. Vaßen, H. Kaßner, G. Mauer, D. Stöver, Suspension Plasma Spraying: Process Characteristics and Applications, J. Therm. Spray Technol., 19(1-2), 219-225 (2010)

3. S. Rezanka, G. Mauer, R. Vaßen, Improved Thermal Cycling Durability of Thermal Barrier Coatings Manufactured by PS-PVD, J. Therm. Spray Technol., 23(1-2), 182$189(2014)$

4. N. Curry, K. VanEvery, T. Snyder, J. Susnjar, S. Bjorklund, Performance Testing of Suspension Plasma Sprayed Thermal Barrier Coatings Produced with Varied Suspension Parameters, Coatings, 5(3), 338-356 (2015) (in English)

5. N. Curry, K. VanEvery, T. Snyder, N. Markocsan, Thermal Conductivity Analysis and Lifetime Testing of Suspension Plasma-Sprayed Thermal Barrier Coatings, Coatings, 4(3), 630-650 (2014)

6. B. Bernard, L. Bianchi, A. Malié, A. Joulia, B. Rémy, Columnar suspension plasma sprayed coating microstructural control for thermal barrier coating application, J. Eur. Ceram. Soc., 36(4), 1081-1089 (2016)

7. W. Fan, Y. Bai, J.R. Li, Y. Gao, H.Y. Chen, Y.X. Kang, W.J. Shi, B.Q. Li, Microstructural design and properties of supersonic suspension plasma sprayed thermal barrier coatings, J. Alloys Compd., 699, 763-774 (2017)

8. B. Bernard, A. Quet, L. Bianchi, A. Joulia, A. Malié, V. Schick, B. Rémy, Thermal insulation properties of YSZ coatings: Suspension Plasma Spraying (SPS) versus 
Electron Beam Physical Vapor Deposition (EB-PVD) and Atmospheric Plasma Spraying (APS), Surf. Coat. Technol., 318, 122-128 (2017)

9. D. Zhou, O. Guillon, R. Vaßen, Development of YSZ Thermal Barrier Coatings Using Axial Suspension Plasma Spraying, Coatings, 7(8), 120 (2017)

10. A. Ganvir, S. Joshi, N. Markocsan, R. Vassen, Tailoring columnar microstructure of axial suspension plasma sprayed TBCs for superior thermal shock performance, Materials \& Design, 144, 192-208 (2018)

11. D. Hanft, J. Exner, M. Schubert, T. Stöcker, P. Fuierer, R. Moos, An Overview of the Aerosol Deposition Method: Process Fundamentals and New Trends in Materials Applications, J. Ceram. Sci. Technol., 6(3), 147-182 (2015)

12. B. Selvan, K. Ramachandran, B.C. Pillai, D. Subhakar, Numerical Modelling of Ar-N2 Plasma Jet Impinging on a Flat Substrate, J. Therm. Spray Technol., 20(3), 534-548 (2011)

13. K. Pourang, C. Moreau, A. Dolatabadi, Effect of Substrate and Its Shape on in-Flight Particle Characteristics in Suspension Plasma Spraying, J. Therm. Spray Technol., 25(1-2), 44-54 (2016)

14. K. VanEvery, M.J.M. Krane, R.W. Trice, H. Wang, W. Porter, M. Besser, D. Sordelet, J. Ilavsky, J. Almer, Column Formation in Suspension Plasma-Sprayed Coatings and Resultant Thermal Properties, J. Therm. Spray Technol., 20(4), 817-828 (2011)

15. P. Sokołowski, S. Kozerski, L. Pawłowski, A. Ambroziak, The key process parameters influencing formation of columnar microstructure in suspension plasma sprayed zirconia coatings, Surf. Coat. Technol., 260, 97-106 (2014)

16. P. Sokołowski, L. Pawłowski, D. Dietrich, T. Lampke, D. Jech, Advanced Microscopic Study of Suspension Plasma-Sprayed Zirconia Coatings with Different Microstructures, J. Therm. Spray Technol., 25(1-2), 94-104 (2016)

17. O. Racek, The Effect of HVOF Particle-Substrate Interactions on Local Variations in the Coating Microstructure and the Corrosion Resistance, J. Therm. Spray Technol., 19(5), 841-851 (2010) 
18. P.L. Fauchais, J.V.R. Heberlein, M.I. Boulos, Thermal Spray Fundamentals: From Powder to Part, Springer, 2014

19. F. Bahbou, P. Nylén, Relationship between surface topography parameters and adhesion strength for plasma spraying, Thermal Spray 2005: Thermal Spray Connects: Explore Its Surfacing Potential!, E. Lugscheider Ed., May 2-4, 2005 (Basel, Switzerland), DVS-German Welding Society, pp 1027-1031

20. P. Fauchais, M. Vardelle, A. Vardelle, S. Goutier, What Do We Know, What are the Current Limitations of Suspension Plasma Spraying? , J. Therm. Spray Technol., 24(7), 1120-1129 (2015)

21. R.C. Seshadri, G. Dwivedi, V. Viswanathan, S. Sampath, Characterizing Suspension Plasma Spray Coating Formation Dynamics through Curvature Measurements, J. Therm. Spray Technol., 25(8), 1666-1683 (2016)

22. Y. Zhao, Z. Yu, M.-P. Planche, A. Lasalle, A. Allimant, G. Montavon, H. Liao, Influence of Substrate Properties on the Formation of Suspension Plasma Sprayed Coatings, J. Therm. Spray Technol., 27(1-2), 73-83 (2018)

23. M. Gupta, N. Markocsan, X.-H. Li, L. Östergren, Influence of Bondcoat Spray Process on Lifetime of Suspension Plasma-Sprayed Thermal Barrier Coatings, J. Therm. Spray Technol., 27(1-2), 84-97 (2018)

24. B. Bernard, A. Quet, L. Bianchi, V. Schick, A. Joulia, A. Malié, B. Rémy, Effect of Suspension Plasma-Sprayed YSZ Columnar Microstructure and Bond Coat Surface Preparation on Thermal Barrier Coating Properties, J. Therm. Spray Technol., 26(23), 1025-1037 (2017)

25. A. Farrokhpanah, T.W. Coyle, J. Mostaghimi, Numerical Study of Suspension Plasma Spraying, J. Therm. Spray Technol., 26(1-2), 12-36 (2017)

26. J. Oberste-Berghaus, S. Bouaricha, J.-G. Legoux, C. Moreau, Injection conditions and in-flight particle states in suspension plasma spraying of alumina and zirconia nano-ceramics, Thermal Spray 2005: Thermal Spray Connects: Explore Its Surfacing 
Potential!, E. Lugscheider Ed., May 2-4, 2005 (Basel, Switzerland), DVS-German Welding Society, pp 512-518

27. P. Wang, W. He, G. Mauer, R. Mücke, R. Vaßen, Monte Carlo simulation of column growth in plasma spray physical vapor deposition process, Surf. Coat. Technol., 335, 188-197 (2018)

28. M. Parmar, A. Haselbacher, S. Balachandar, Generalized Basset-Boussinesq-Oseen equation for unsteady forces on a sphere in a compressible flow, Phys. Rev. Lett., 106(8), $084501(2011)$

29. L. von Schiller, N. Naumann, Über die grundlegenden Berechnungen bei der Schwerkraftaufbereitung, VDI Zeitschrift (1857-1968), 77(12), 318-320 (1933)

30. E. Loth, Compressibility and Rarefaction Effects on Drag of a Spherical Particle, AIAA J., 46(9), 2219-2228 (2008)

31. G.A. Bird, Definition of mean free path for real gases, The Physics of Fluids, 26(11), $3222-3223(1983)$

32. X. Chen, E. Pfender, Effect of the Knudsen Number on Heat Transfer to a Particle Immersed into a Thermal Plasma, Plasma Chem. Plasma Process., 3(1), 97-113 (1983)

33. X. Chen, X. Chen, Drag on a Metallic or Nonmetallic Particle Exposed to a Rarefied Plasma Flow, Plasma Chem. Plasma Process., 9(3), 387-408 (1989)

34. X. Chen, P. He, Heat Transfer from a Rarefied Plasma Flow to a Metallic or Nonmetallic Particle, Plasma Chem. Plasma Process., 6(4), 313-333 (1986)

35. Y.P. Chyou, E. Pfender, Behavior of particulates in thermal plasma flows, Plasma Chem. Plasma Process., 9(1), 45-71 (1989)

36. D.J. Rader, Momentum Slip Correction Factor for Small Particles in Nine Common Gases, J. Aerosol Sci., 21(2), 161-168 (1990)

37. J.H. Kim, G.W. Mulholland, S.R. Kukuck, D.Y.H. Pui, Slip Correction Measurements of Certified PSL Nanoparticles Using a Nanometer Differential Mobility Analyzer 
(Nano-DMA) for Knudsen Number From 0.5 to 83, J. Res. Natl. Inst. Stand. Technol., 110(1), 31-54 (2005)

38. E. Cunningham, On the Velocity of Steady Fall of Spherical Particles through Fluid Medium, Proc. R. Soc. London, Ser. A, 83, 357-365 (1910)

39. C. Delbos, J. Fazilleau, V. Rat, J.F. Coudert, P. Fauchais, B. Pateyron, Phenomena Involved in Suspension Plasma Spraying Part 2: Zirconia Particle Treatment and Coating Formation, Plasma Chem. Plasma Process., 26(4), 393-414 (2006)

40. C.G. Phillips, S.R. Kaye, The Influence of the Viscous Boundary Layer on the Critical Stokes Number for Particle Impaction Near a Stagnation Point, J. Aerosol Sci., 30(9), 709-718 (1999)

41. E. Pohlhausen, Der Wärmeaustausch zwischen festen Körpern und Flüssigkeiten mit kleiner reibung und kleiner Wärmeleitung, ZAMM - Journal of Applied Mathematics and Mechanics / Zeitschrift für Angewandte Mathematik und Mechanik, 1(2), 115-121 (1921) (in German)

42. H. Schlichting, K. Gersten, Grenzschichttheorie, Springer, 2006

43. G. Mauer, R. Vaßen, Conditions for nucleation and growth in the substrate boundary layer at plasma spray-physical vapor deposition (PS-PVD), Surf. Coat. Technol., (2018) (in https://doi.org/10.1016/j.surfcoat.2018.06.086)

44. C.d. Donaldson, R.S. Snedeker, A study of free jet impingement. Part 1. Mean properties of free and impinging jets, Journal of Fluid Mechanics, 45(2), 281-319 (2006)

45. A. Mahdavi, A. McDonald, Analytical study of the heat transfer coefficient of the impinging air jet during cold spraying, International Journal of Thermal Sciences, 130, 289-297 (2018)

46. W. He, G. Mauer, M. Gindrat, R. Wäger, R. Vaßen, Investigations on the Nature of Ceramic Deposits in Plasma Spray-Physical Vapor Deposition, J. Therm. Spray Technol., 26(1), 83-92 (2017) 
47. S. Gordon, B.J. McBride, Computer Program for Calculation of Complex Chemical Equilibrium Compositions and Applications - Analysis. NASA-Reference Publication, 1311 part 1, NASA Lewis Research Center, 1994

48. S. Gordon, B.J. McBride, Computer Program for Calculation of Complex Chemical Equilibrium Compositions and Applications - User's Manual and Program Description. NASA-Reference Publication 1311, part 2, NASA Lewis Research Center, 1996

49. M. Vardelle, Armelle Vardelle, P. Fauchais, M.I. Boulos, Plasma-Particle Momentum and Heat Transfer: Modelling and Measurements, AlChE J., 29(2), 238-243 (1983)

50. G. Mauer, A. Hospach, N. Zotov, R. Vaßen, Process Conditions and Microstructures of Ceramic Coatings by Gas Phase Deposition Based on Plasma Spraying, J. Therm. Spray Technol., 22(2-3), 83-89 (2013)

51. G. Mauer, Plasma Characteristics and Plasma-Feedstock Interaction Under PS-PVD Process Conditions, Plasma Chem. Plasma Process., 34(5), 1171-1186 (2014)

52. M. Jadidi, M. Mousavi, S. Moghtadernejad, A. Dolatabadi, A Three-Dimensional Analysis of the Suspension Plasma Spray Impinging on a Flat Substrate, J. Therm. Spray Technol., 24(1-2), 11-23 (2015)

53. M. Jadidi, A.Z. Yeganeh, A. Dolatabadi, Numerical Study of Suspension HVOF Spray and Particle Behavior Near Flat and Cylindrical Substrates, J. Therm. Spray Technol., 27(1-2), 59-72 (2018)

54. W. He, G. Mauer, M. Gindrat, R. Wäger, R. Vaßen, Investigations on the Nature of Ceramic Deposits in Plasma Spray-Physical Vapor Deposition, J. Therm. Spray Technol., 26(1-2), 83-92 (2016)

55. G. Mauer, R. Vaßen, Plasma Spray-PVD: Plasma Characteristics and Impact on Coating Properties, J. Phys.: Conf. Ser., 406, 012005 (2012)

56. F.M. White, Viscous Fluid Flow, $2^{\text {nd }}$ ed., McGraw-Hill, 1991 


\section{Figures}

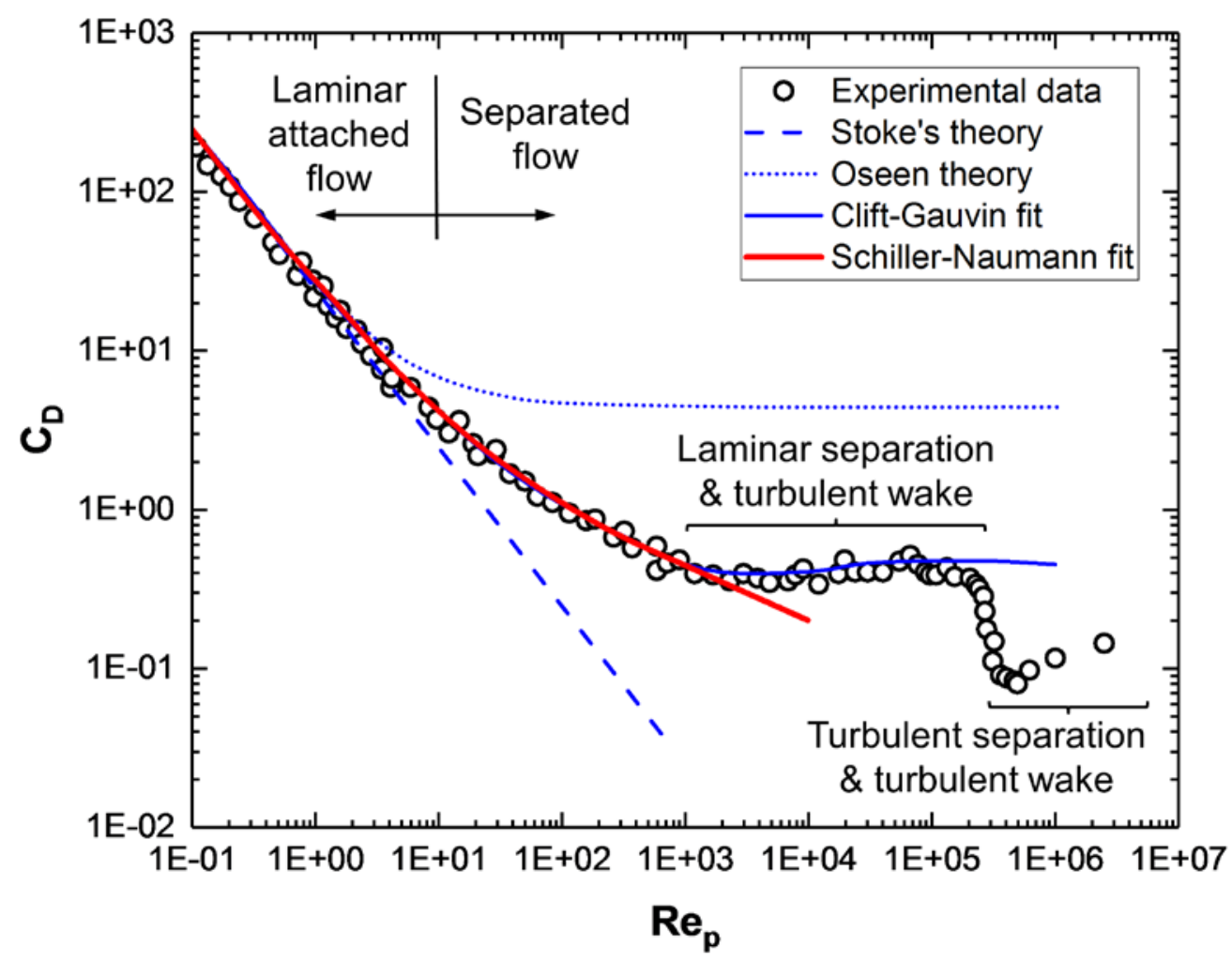

Figure 1: Comparison of experimental data with different fits of the drag coefficient $C_{D}$ as a function of the particle Reynolds number $R e_{p}$; redrawn after E. Loth (Ref 30) with experimental data reported by White (Ref 56). 


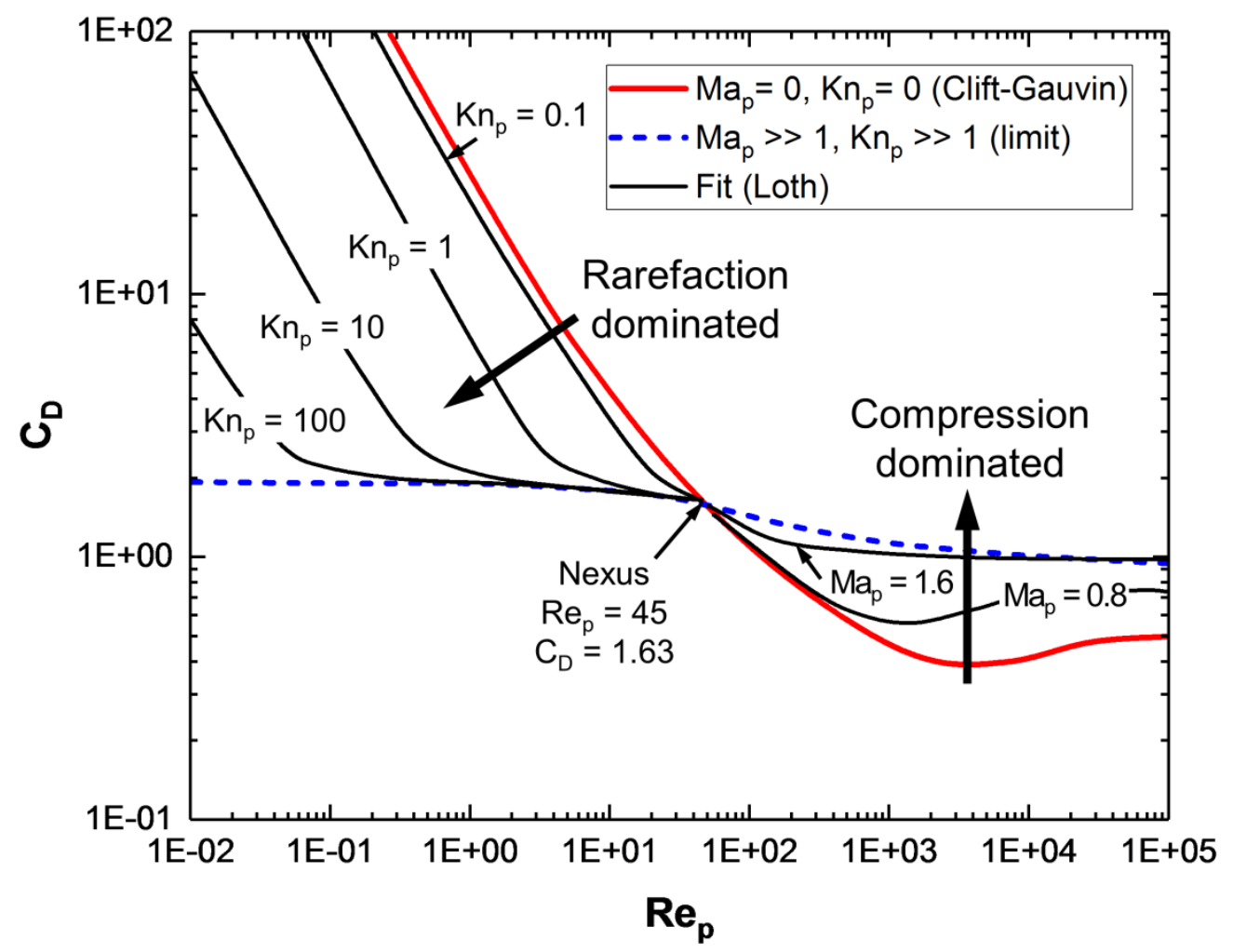

Figure 2: Rarefaction and compression dominated regimes of the drag coefficient $C_{D}$ as a function of the particle Reynolds number $\mathrm{Re}_{\mathrm{p}}$; redrawn after Loth (Ref 30). 


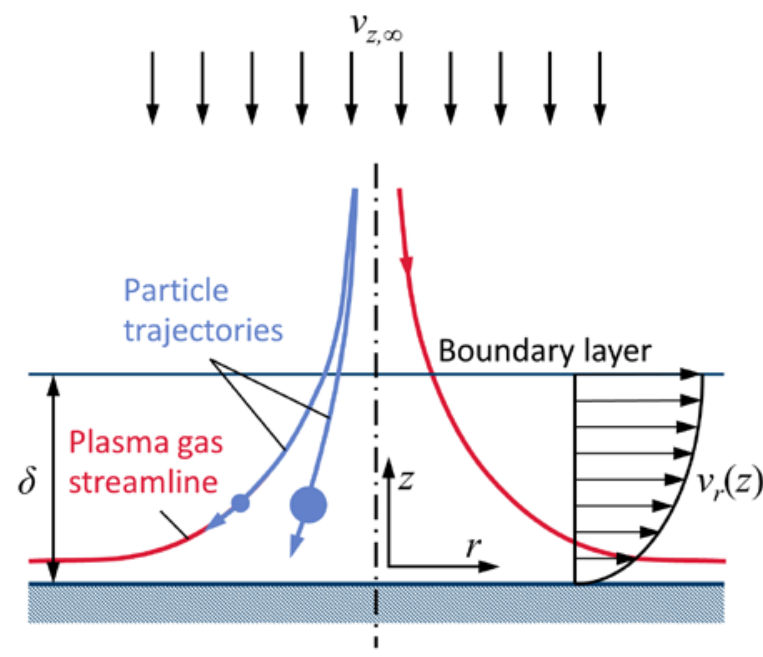

Figure 3: Boundary layer flow model of an axisymmetric flow onto a plate with plasma gas streamlines and particle trajectories (schematic). 


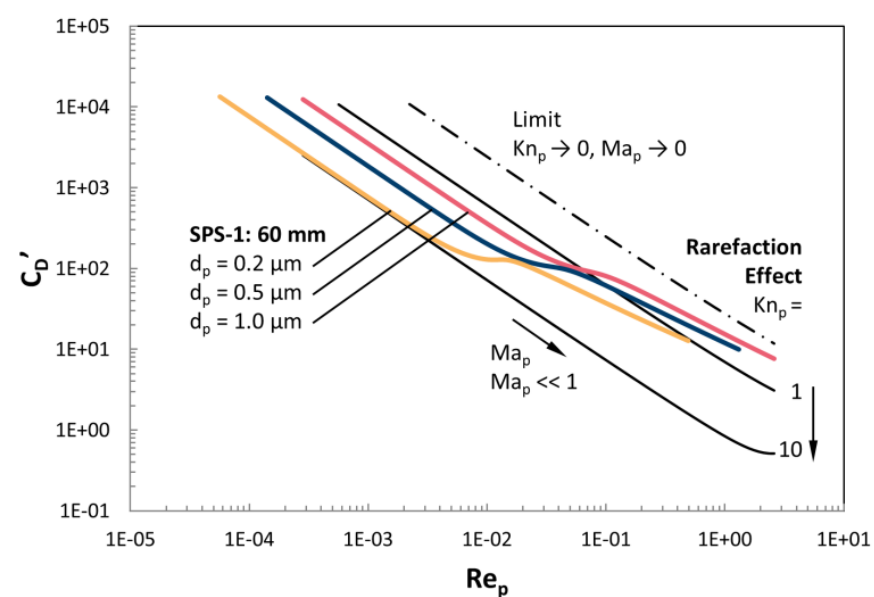

Figure 4: Development of the drag coefficients as a function of particle Reynolds numbers calculated along the particle trajectories from entering the BL (left hand on the diagram) until impact on the substrate surface (right hand on the diagram) for particles with three different diameters; SPS-1: $60 \mathrm{~mm}$ spray distance. 


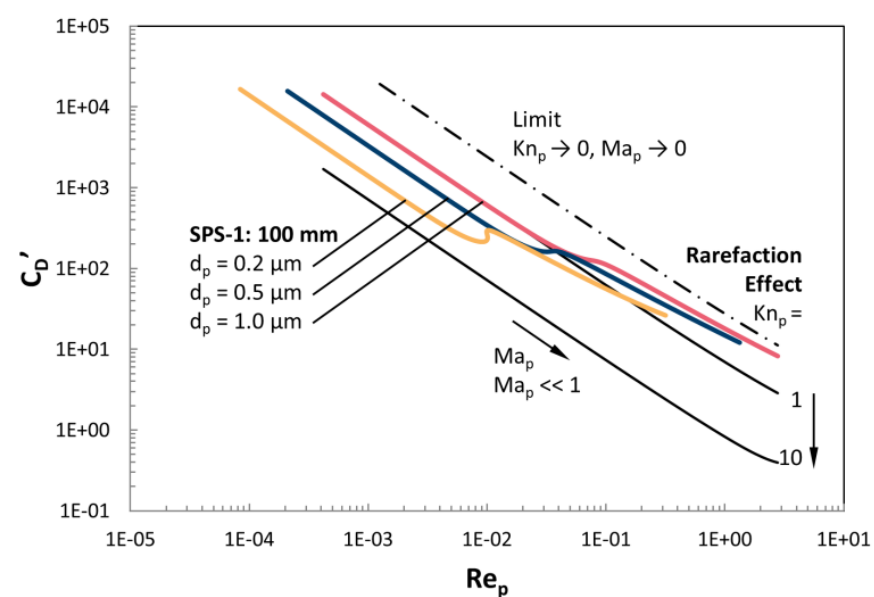

Figure 5: Development of the drag coefficients as a function of particle Reynolds numbers calculated along the particle trajectories from entering the BL (left hand on the diagram) until impact on the substrate surface (right hand on the diagram) for particles with three different diameters;SPS-1: $100 \mathrm{~mm}$ spray distance. 


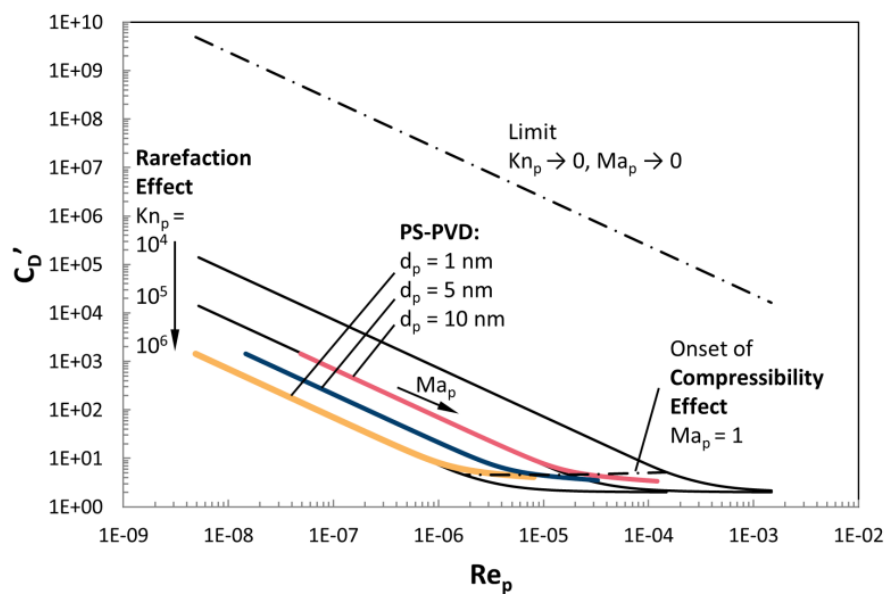

Figure 6: Development of the drag coefficients as a function of particle Reynolds numbers calculated along the particle trajectories from entering the BL (left hand on the diagram) until impact on the substrate surface (right hand on the diagram) for particles with three different diameters; PS-PVD process conditions. 


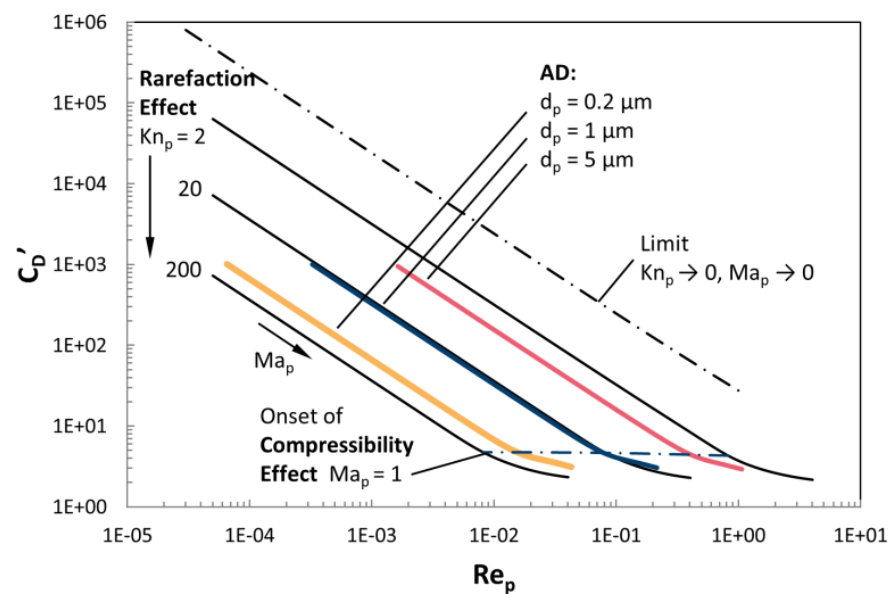

Figure 7: Development of the drag coefficients as a function of particle Reynolds numbers calculated along the particle trajectories from entering the BL (left hand on the diagram) until impact on the substrate surface (right hand on the diagram) for particles with three different diameters; $A D$ process conditions. 


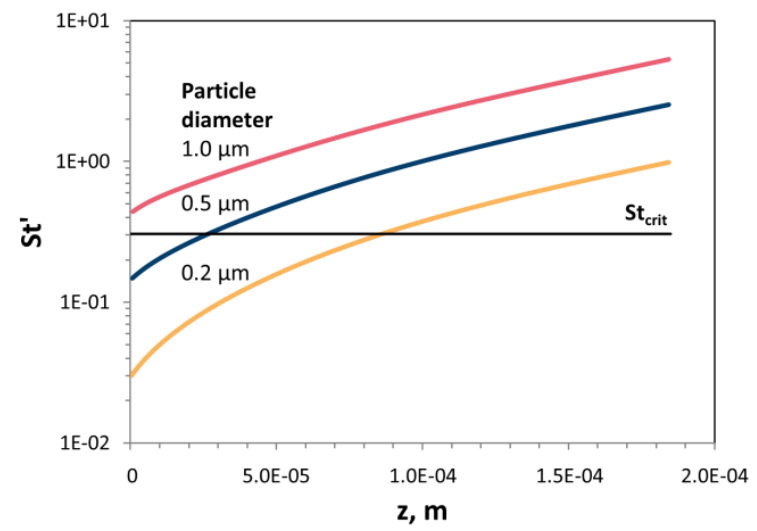

Figure 8: Stokes numbers and critical value along the trajectories of three different particle sizes plotted against the normal $z$ coordinate through the $B L$ (substrate surface at $z=0$ ); process conditions SPS-1: $60 \mathrm{~mm}$ spray distance. 


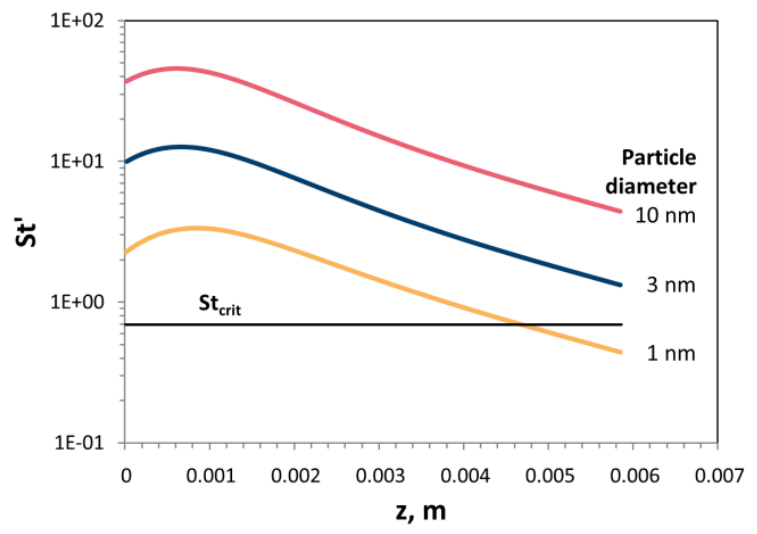

Figure 9: Stokes numbers and critical value along the trajectories of three different particle sizes plotted against the normal $z$ coordinate through the $B L$ (substrate surface at $z=0$ ); process conditions PS-PVD. 


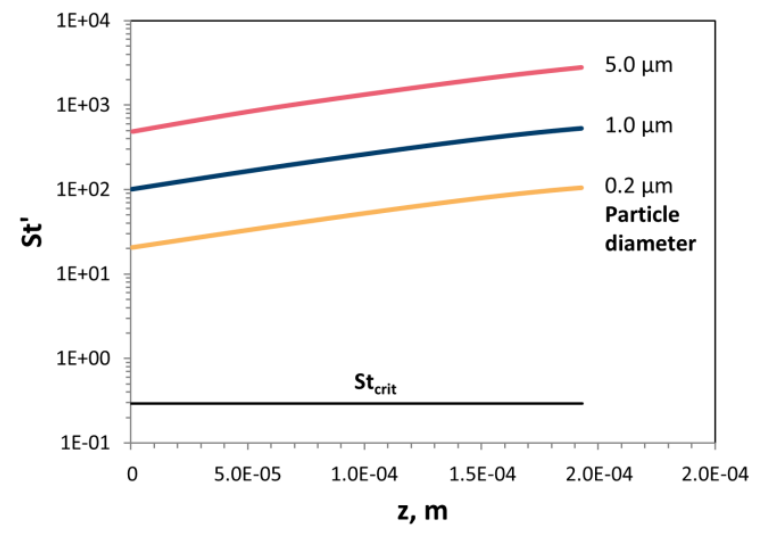

Figure 10: Stokes numbers and critical value along the trajectories of three different particle sizes plotted against the normal $z$ coordinate through the $B L$ (substrate surface at $z=0$ ); process conditions $A D$. 


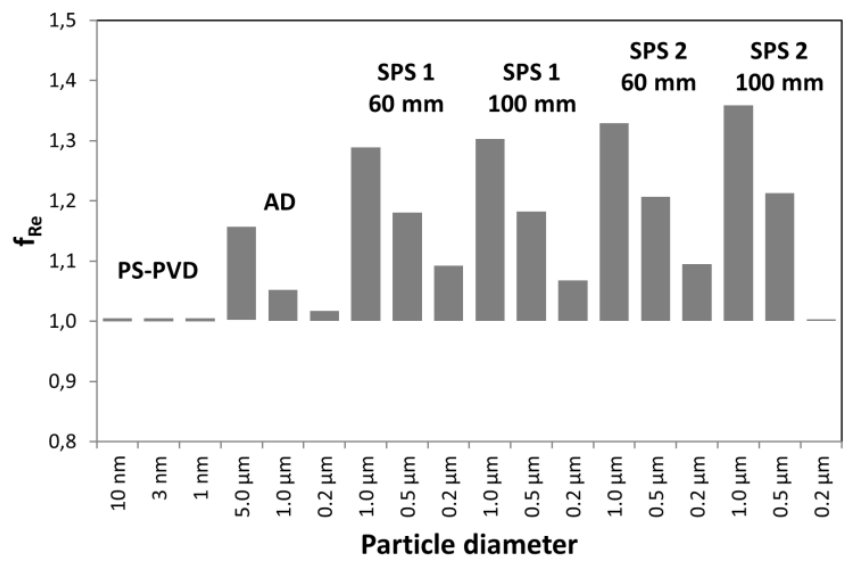

Figure 11: Summary of the value domains of the Reynolds correction factor found for the different spray processes and three typical particle sizes in each case. 


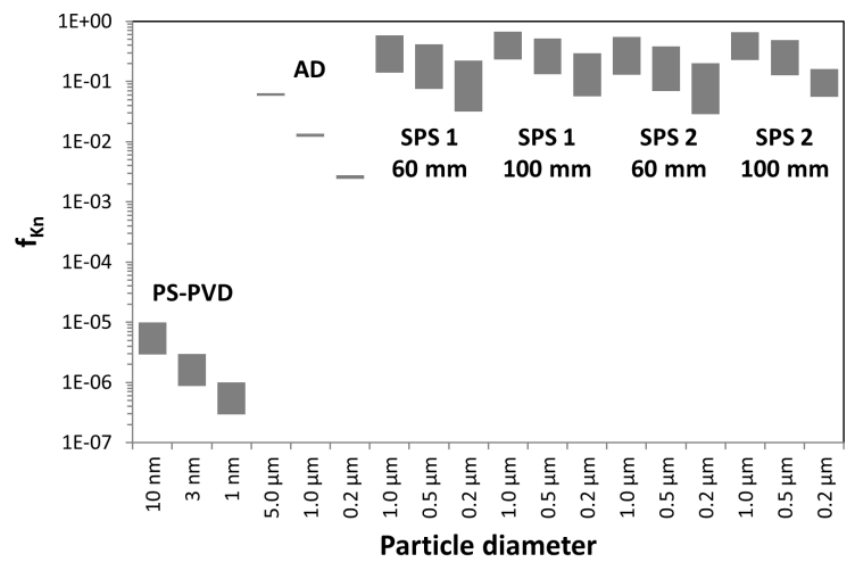

Figure 12: Summary of the value domains of the slip correction factor found for the different spray processes and three typical particle sizes in each case. 


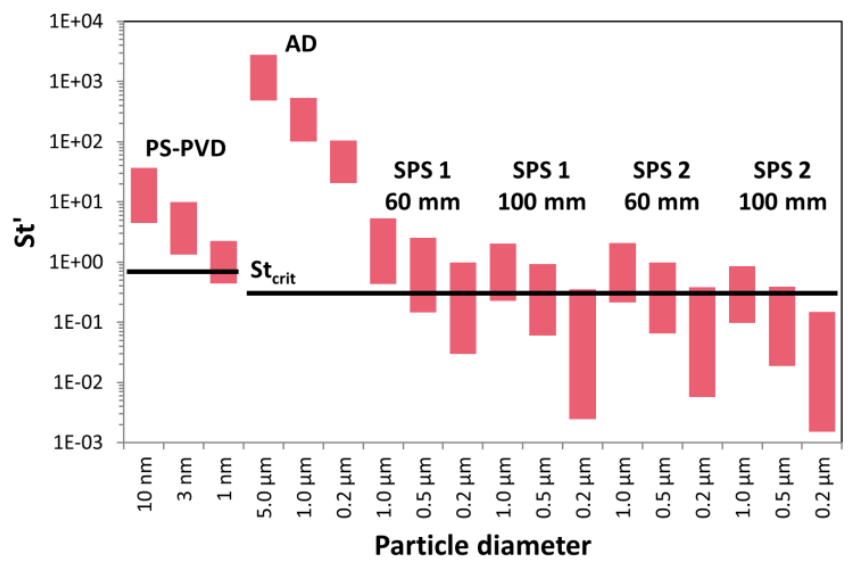

Figure 13: Summary of the value domains of the Stokes numbers found for the different spray processes and three typical particle sizes in each case; the corresponding critical Stokes numbers are indicated by horizontal lines. 